\title{
Mental Health and Burnout Syndrome Among Postgraduate Students in Medical and Multidisciplinary Residencies During the COVID-19 Pandemic in Brazil: Protocol for a Prospective Cohort Study
}

Rebeca Da Nóbrega Lucena Pinho ${ }^{1,2}$, MS; Thais Ferreira Costa $^{3}$, MD; Nayane Miranda Silva ${ }^{1,2}$, MS; Adriana F Barros-Areal $^{1,3}$, MD; André De Mattos Salles ${ }^{2}, \mathrm{MD}$; Andrea Pedrosa Oliveira ${ }^{2,4}, \mathrm{MD}, \mathrm{PhD}$; Carlos Rassi ${ }^{4,5}, \mathrm{MD}, \mathrm{PhD}$; Caroline Elizabeth Brero Valero ${ }^{6}, \mathrm{MSc}$; Ciro Martins Gomes ${ }^{1,2,7}, \mathrm{MD}, \mathrm{PhD}$; Dayde Mendonça-Silva ${ }^{4}, \mathrm{PhD}$; Fernando Oliveira $^{4}$, MSc; Isadora Jochims ${ }^{2}$, MD, MSc; Ivan Ranulfo ${ }^{1,4}$, MD; Juliana De Brito Seixas Neves ${ }^{6}$, MS; Lucas Oliveira $^{8}$, MD; Maria Nogueira Dantas ${ }^{6}$, MS; Marta Rosal ${ }^{9}$, MD; Mayra Soares ${ }^{2}$, MD; Patrícia Kurizky ${ }^{1,2}$, MD, PhD; Viviane Uliana Peterle ${ }^{10}$, MD, PhD; Yasmin Furtado Faro ${ }^{2}$, MD; Ana Paula Gomides ${ }^{11}$, MD, PhD; Licia da Mota ${ }^{1,2}$, $\mathrm{MD}, \mathrm{PhD}$; Cleandro Albuquerque ${ }^{1,2}, \mathrm{MD}, \mathrm{MSc}$; Cezar Kozak Simaan ${ }^{4}, \mathrm{MD}, \mathrm{MSc}$; Veronica M Amado ${ }^{4}, \mathrm{MD}, \mathrm{PhD}$

\footnotetext{
${ }^{1}$ Programa de Pós-Graduação em Ciências Médicas FM-UnB, Brasília, Brazil

${ }^{2}$ Hospital Universitário de Brasília - HUB-UnB, Brasília, Brazil

${ }^{3}$ Secretaria de Estado de Saúde do Distrito Federal - SES DF, Brasília, Brazil

${ }^{4}$ Universidade de Brasília - UnB, Brasília, Brazil

${ }^{5}$ Hospital Sírio-Libanês, Brasília, Brazil

${ }^{6}$ Empresa Brasileira de Serviços Hospitalares - EBSERH, Brasília, Brazil

${ }^{7}$ Núcleo de Medicina Tropical, Universidade de Brasília - UnB, Brasília, Brazil

${ }^{8}$ Faculdade de Medicina, Universidade de Brasília FM-UnB., Brasília, Brazil

${ }^{9}$ Universidade Federal do Piauí - UFPI, Teresina, Brazil

${ }^{10}$ Escola Superior de Ciências da Saúde / ESCS, Brasília, Brazil

${ }^{11}$ Centro Universitário de Brasília - Uniceub, Brasília, Brazil
}

\section{Corresponding Author:}

Rebeca Da Nóbrega Lucena Pinho, MS

Programa de Pós-Graduação em Ciências Médicas FM-UnB

SGAN 605, Av. L2 Norte

Brasília

Brazil

Phone: 5561983436834

Email: nlp.rebeca@gmail.com

\section{Abstract}

Background: The COVID-19 pandemic has led to high levels of physical, psychological, and social stress among health care professionals, including postgraduate students in medical and multidisciplinary residencies. This stress is associated with the intense fear of occupational exposure to SARS-CoV-2, the virus known to cause COVID-19. These professionals are at risk of developing physical and mental illnesses not only due to the infection but also due to prolonged exposure to multidimensional stress and continued work overload.

Objective: This study aims to evaluate the prevalence of symptoms suggestive of mental disorders and burnout syndrome and determine the risk factors for burnout among postgraduate students in medical and multidisciplinary residencies in Brazil during the COVID-19 pandemic.

Methods: For this prospective cohort study with parallel groups, participants were recruited between July and September 2020 to achieve a sample size of at least 1144 participants. Research instruments such as Depression, Anxiety, and Stress Scale; Patient Health Questionnaire; Brief Resilient Coping Scale; and Oldenburg Burnout Inventory will be used to collect data. Data will be collected in 2 waves: the first wave will include data related to sample characterization and psychosocial evaluation, and the 
second wave will be launched 12 weeks later and will include an evaluation of the incidence of burnout as well as correlations with the potential predictive factors collected in the first wave. Additionally, we will collect data regarding participants' withdrawal from work.

Results: The recruitment took place from July 29 to September 5, 2020. Data analyses for this phase is already in progress. The second phase of the study is also in progress. The final data collection began on December 1, 2020, and it will be completed by December 31, 2020.

Conclusions: We believe the findings of this study will help evaluate the impact of the COVID-19 pandemic on the mental health conditions of health professionals in Brazil as well as contribute to the planning and implementation of appropriate measures that can alleviate these mental health challenges.

International Registered Report Identifier (IRRID)： DERR1-10.2196/24298

(JMIR Res Protoc 2021;10(1):e24298) doi: $\underline{10.2196 / 24298}$

\section{KEYWORDS}

burnout syndrome; medical residency; multidisciplinary residency; COVID-19; mental health; burnout; stress; anxiety; prospective; cohort; health care professional; medical student

\section{Introduction}

The first COVID-19 outbreak occurred in Wuhan, China, at the end of 2019, and it rapidly spread across the world. On January 30, 2020, the World Health Organization declared that the outbreak constituted a public health emergency of international importance and characterized COVID-19 as a pandemic on March 11, 2020 [1].

During this pandemic, health care professionals, including postgraduate students in medical residency and multidisciplinary programs, have been directly involved in disease management, and consequently, they are exposed to an increased risk of infection due to direct contact with infected patients [2]. Additionally, most of these professionals are likely to develop psychological distress and other mental health-related symptoms, which may be attributed to the lack of security in the face of the unprecedented scenario, increase in the number of confirmed COVID-19 cases, work overload, shortage of diagnostic tests and personal protective equipment (PPE), and the lack of specific drugs for treatment, among other factors [3].

Mental disorders among health care professionals have been the focus of many scientific studies in recent years. A high prevalence of mental health conditions has been reported among the professionals, with a wide spectrum of manifestations correlated to the intense emotional demands and adverse working conditions experienced by them. Physicians and nursing professionals, especially nurses [4], are particularly more susceptible to the development of these problems, in addition to the high levels of work-related stress [5].

In this context, the burnout syndrome stands out. It is defined as a state of physical and mental exhaustion resulting from work activities or care provision, reflected through emotional change and irritability. Burnout is characterized as a psychological syndrome resulting from a continuous response to chronic stressors and interpersonal factors at work. Consequently, psychiatric problems may develop, featuring as emotional exhaustion, depersonalization, and reduced personal achievement [6].
Medical and multidisciplinary residency programs have high workloads and demands; these programs call for many hours of dedication from postgraduate students to fulfill the established requirements. In addition, there can be a significant degree of burnout, which can interfere with the students' decision-making. In general, burnout syndrome is associated with a number of unfavorable consequences such as depression, risk of medical errors, and patient safety risks [5]. Moreover, an increased workload during this critical period of residency has been found to be associated with a decline in the mental health of the residents [6]; these findings have important implications especially in the ongoing pandemic situation.

In recent years, several studies related to burnout syndrome in health care professionals have been published; however, data published in the scientific literature referring to residents are limited [7]. Studies addressing mental health and burnout syndrome among health care professionals in Brazil and worldwide are quite restricted with regard to the number of residents (ie, medical residents and multidisciplinary residents). Additionally, no studies on these disorders have been performed during the COVID-19 pandemic. Therefore, this study aims to evaluate the prevalence of symptoms suggestive of mental disorders and burnout syndrome as well as determine the risk factors for burnout among postgraduate students in medical and multidisciplinary residencies in Brazil during the COVID-19 pandemic.

\section{Methods}

\section{Study Design and Data Collection}

This is a prospective cohort study comprising 2 parallel groups. Baseline evaluation will be performed at the time of recruitment of study participants and will serve as cross-sectional data to estimate the prevalence of symptoms indicative of mental disorders and professional burnout. A longitudinal follow-up will also be performed to enable estimation of the incidence and identification of predictive factors of burnout among the study participants.

Individuals were recruited from July to August 2020 via electronic invitations sent out through the Microsoft Forms 
platform (Microsoft Corp). Two waves of data collection were programmed, including initial data collection and a 12-week follow-up (Figure 1). In the first wave (July 29 to September $5,2020)$, all data related to the characterization of the study sample, including psychosocial assessment and potential predictive factors related to the research outcomes, were collected. In the second wave of data collection (ie, at the 12-week follow-up), the incidence of burnout will be evaluated, which will then be correlated with the potential predictive factors collected during the first wave. Additionally, we will collect data on participants' withdrawal from work.

Figure 1. Study fluxogram.

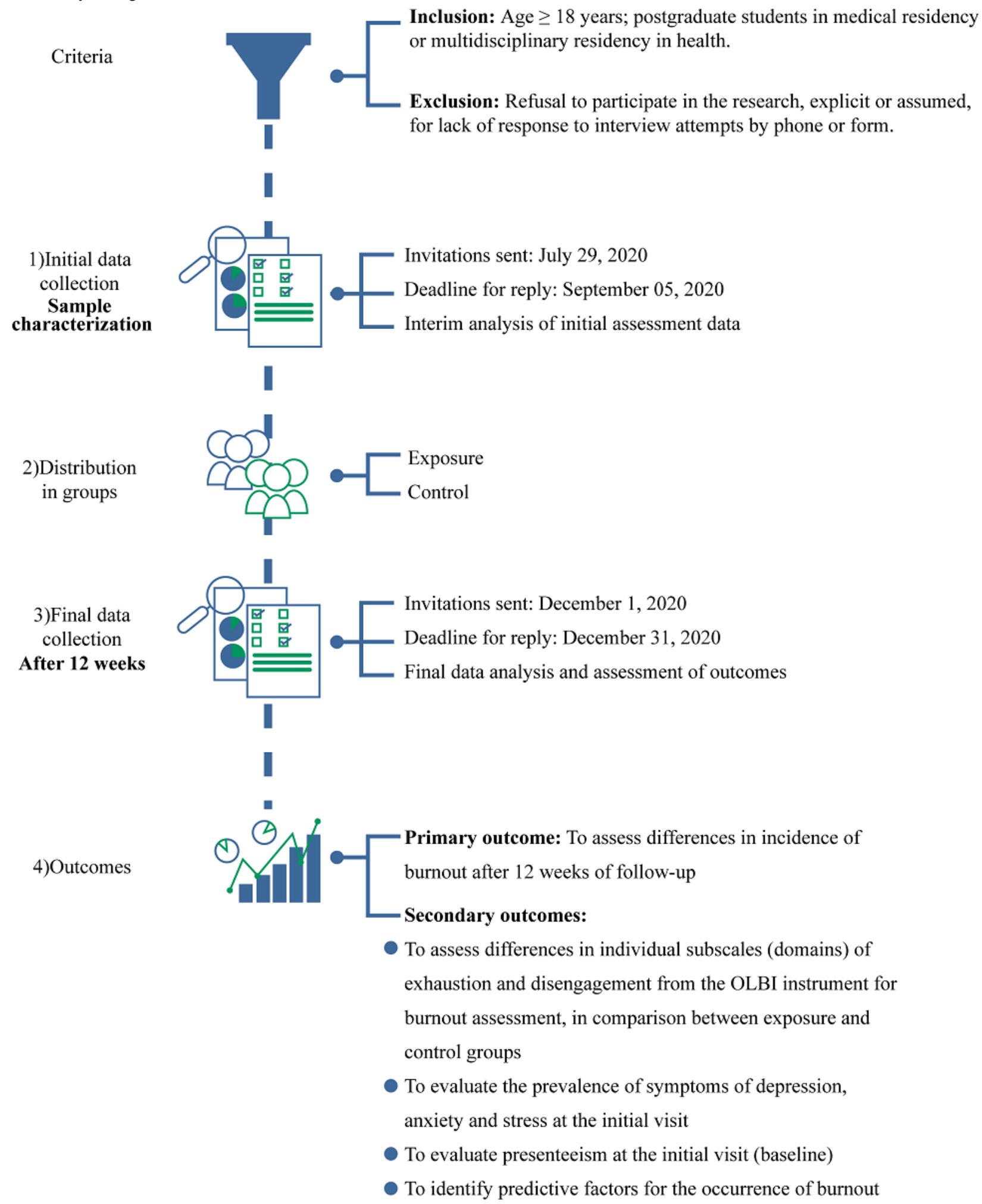




\section{Research Instruments}

\section{Depression, Anxiety, and Stress Scale}

The Depression, anxiety, and stress scale-21 items (DASS-21) scale has been translated and validated in Portuguese [8] and consists of 3 subscales with 7 items each. Responses are given on a 4-point scale, ranging from 0 (strongly disagree) to 3 (totally agree). The DASS-21 covers 3 symptom domains: depression, anxiety, and stress. The cutoff points for each of these domains are as follows: depression $>9$, anxiety $>7$, and stress $>14$ (Textbox 1, [9]).

Textbox 1. Depression, Anxiety, and Stress Scale-21 items (DASS-21) [9]

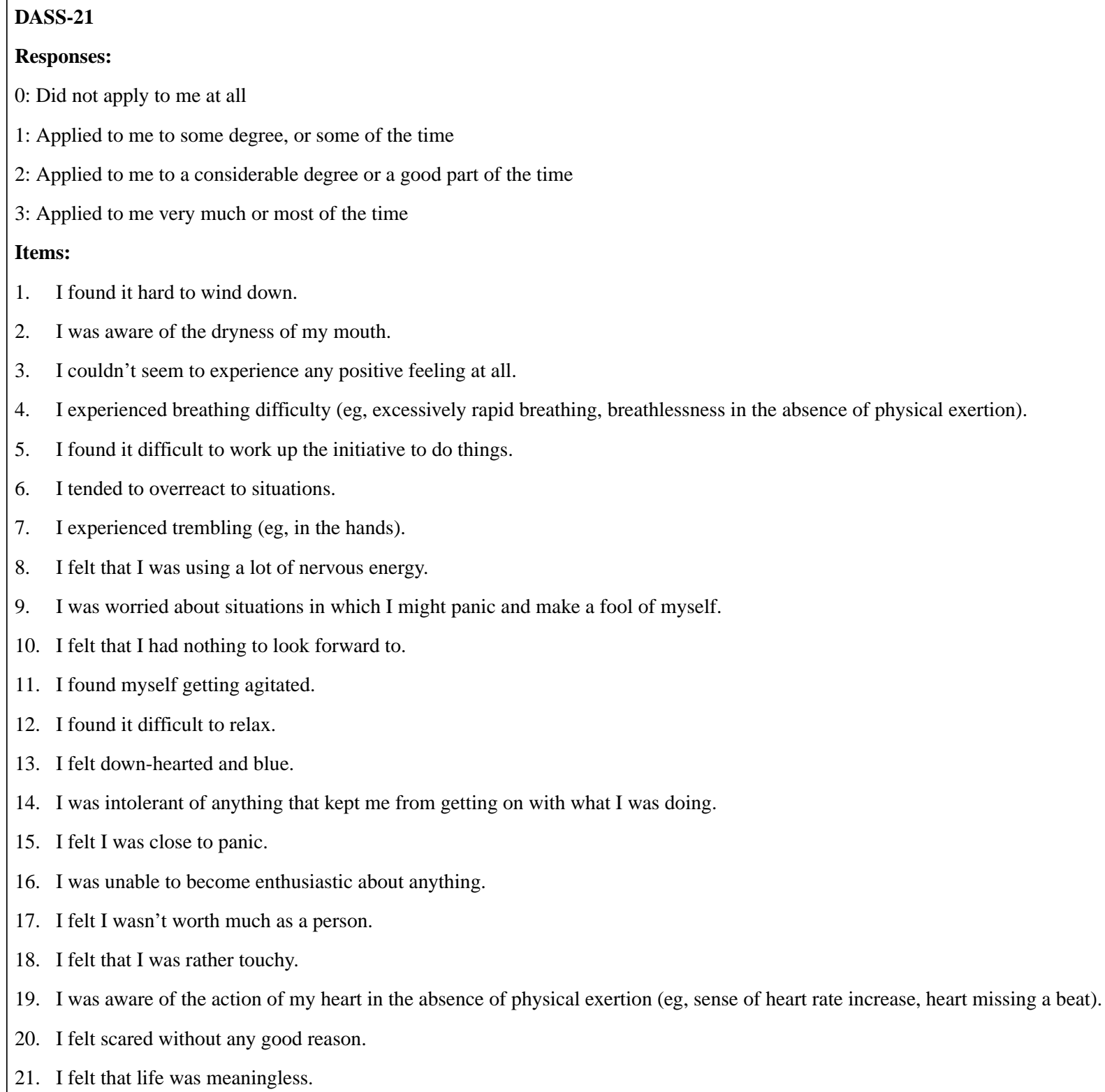

\section{Patient Health Questionnaire}

Patient Health Questionnaire-9 items (PHQ-9) is a rapid assessment tool that has been translated and validated in Portuguese. It has advantages over other instruments currently validated for use in Brazil [10]. It consists of 9 questions for screening depression, with respondents expected to mark responses in relation to the frequency of symptoms they have experienced in the last 2 weeks: 0 , no day; 1 , less than 1 week; 2,1 week or more; and 3, almost every day (Textbox 2, [11]). 
Textbox 2. Patient Health Questionnaire-9 items (PHQ-9) [11].

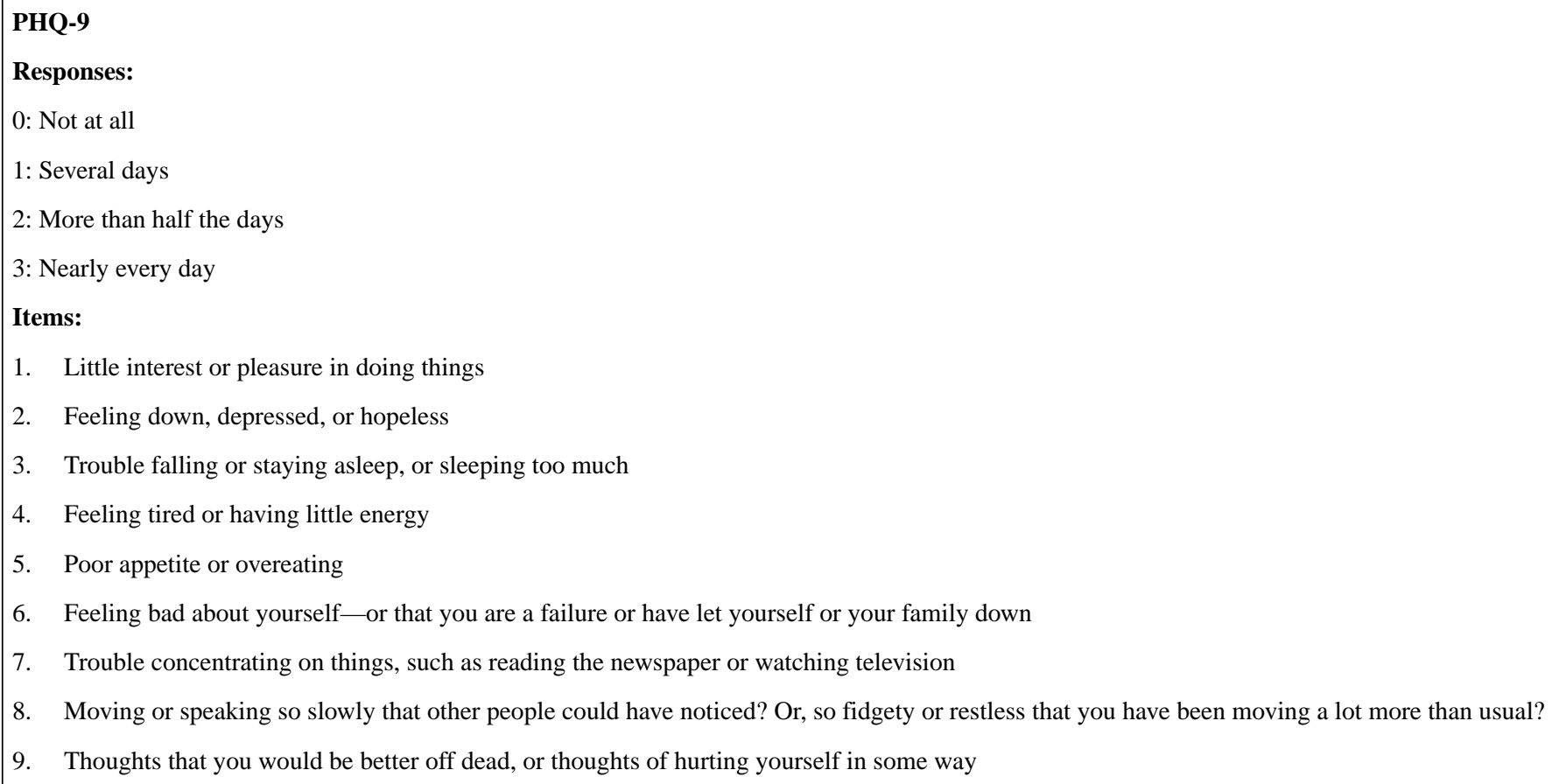

\section{Brief Resilient Coping Scale}

Brief Resilient Coping Scale (BRCS) is a 1D instrument comprising 4 items to assess an individual's ability to deal with stress in an adaptive way [12]. The responses to the questionnaire items are provided on a 5-point scale: 5, almost always; 4, very often; 3, often; 2, occasionally; and 1, almost never. Total scores on the scale range from 4 and 20, and according to its developers, respondents who score less than 13 are considered to have a low level of resilience (Textbox 3, [13]).

Textbox 3. Brief Resilient Coping Scale (BRCS) [13].

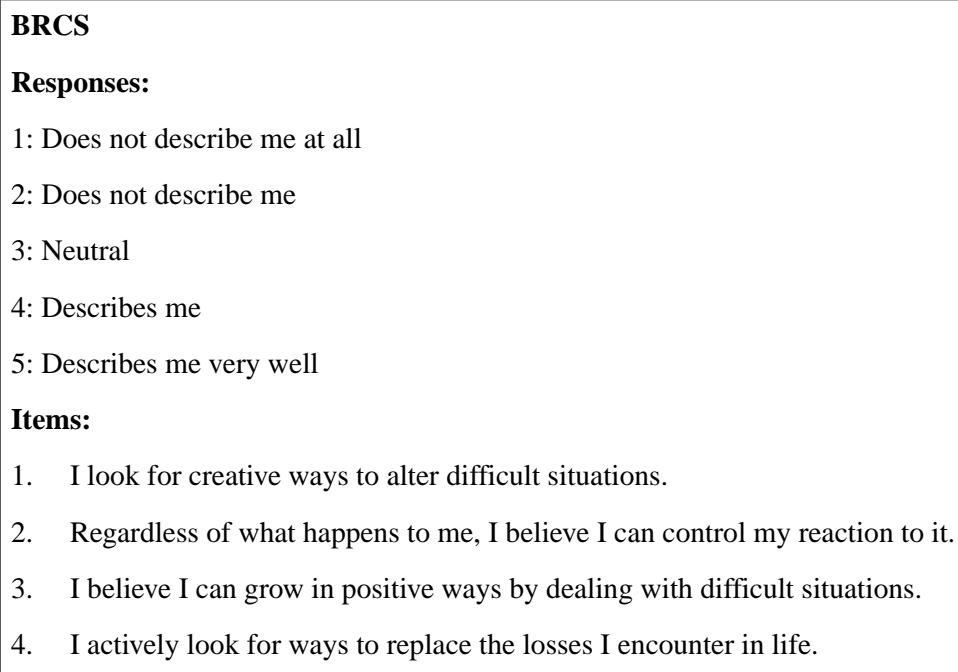

\section{Autonomy Degree Scale to Decide Conduct at Work}

This visual analog scale (VAS) assesses an individual's perception of autonomy at their job. Response options range from 0 to 10 , with 0 indicating "I have no autonomy" and 10 indicating "I have total autonomy." Total scores $\leq 4$ indicate a low level of perceived autonomy at work [14].

\section{Perception of Availability of Personal Protective Equipment}

This single-item instrument was used to assess the availability of personal protective equipment (PPE) for health professionals on a scale of 1 to 5. The question was "In your professional practice, in patient care, for which period of time did you have sufficient and adequate personal protective equipment (PPE) available?" The response options were as follows: 1 , no time; 
2 , less than half the time; 3 , half the time; 4 , more than half the time; and 5 , all the time.

\section{Oldenburg Burnout Inventory}

The Oldenburg Burnout Inventory (OLBI) is used to assess burnout through the development of a cross-culturally adapted version for both Brazil and Portugal [15]. The OLBI is a 5-point self-reported scale: 5 , strongly agree; 4 , agree; 3 , neither agree nor disagree; 2, disagree; and 1, strongly disagree. This 2D scale covers disengagement and exhaustion, and each dimension comprises 8 items. The disengagement dimension refers to the distancing from work in terms of object and content and the development of cynical and negative attitudes and behaviors toward work. The exhaustion dimension refers to feelings of physical fatigue, need for rest, feeling of overload, and emptiness in relation to work (Textbox 4, [16]).

Textbox 4. Oldenburg Burnout Inventory (OLBI) [16].

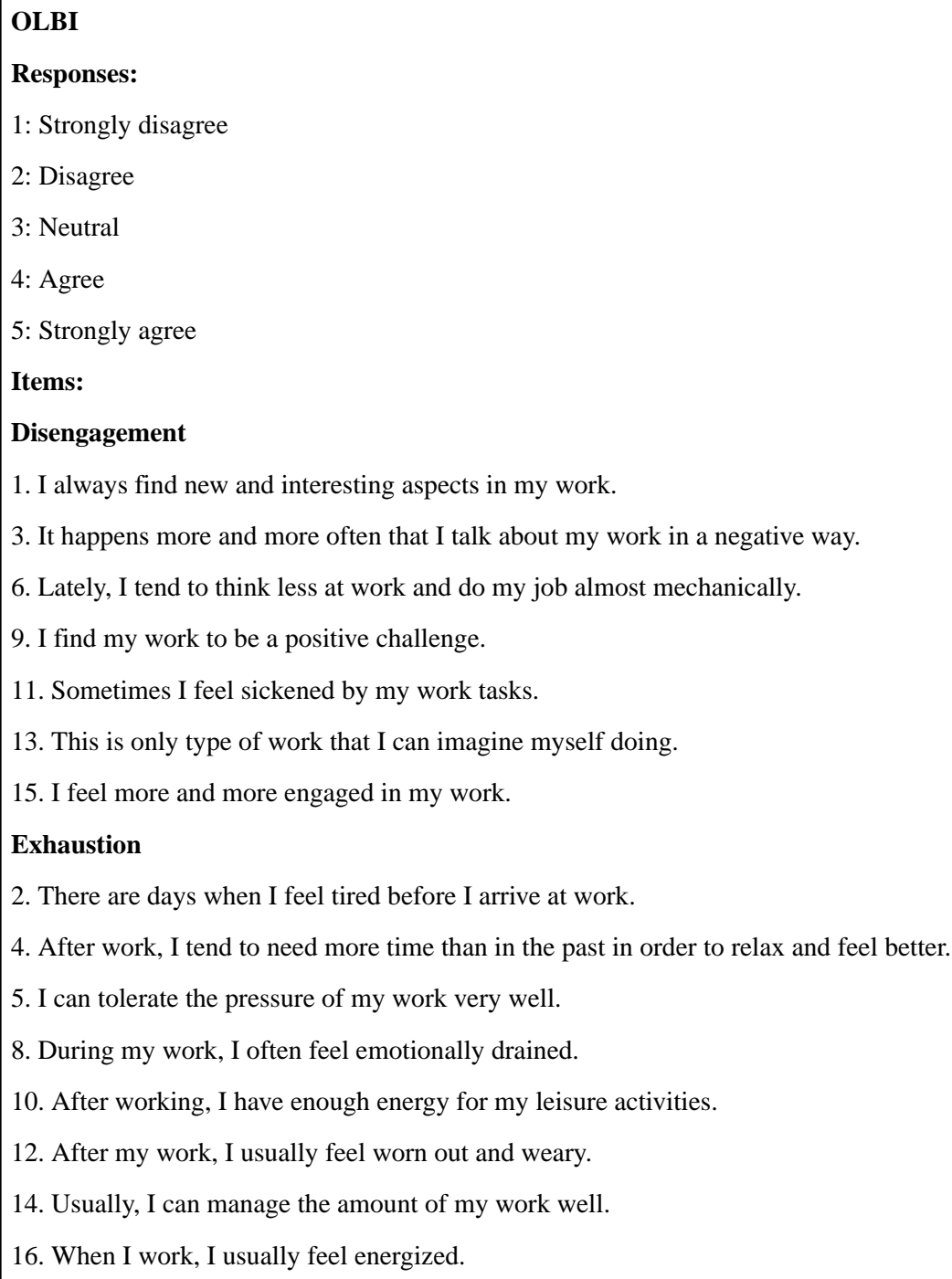

\section{External Work Contract}

This instrument comprises a single "yes" or "no" item to assess the existence of an employment relationship rather than that of a residency.

\section{Providing Care for Patients With COVID-19}

This instrument forms a single "yes" or "no" item to assess whether the respondent provides direct assistance to patients with COVID-19.

\section{Stanford Presenteeism Scale}

The Stanford Presenteeism Scale (SPS-6) exclusively assesses presenteeism. This instrument helps evaluate the relationship between presenteeism, health problems, and productivity among workers. It consists of 6 items, with responses for each item ranging from 1 (strongly disagree) to 5 (strongly agree) (Textbox $5,[17])$. 
Textbox 5. Stanford Presenteeism Scale (SPS-6) [17].

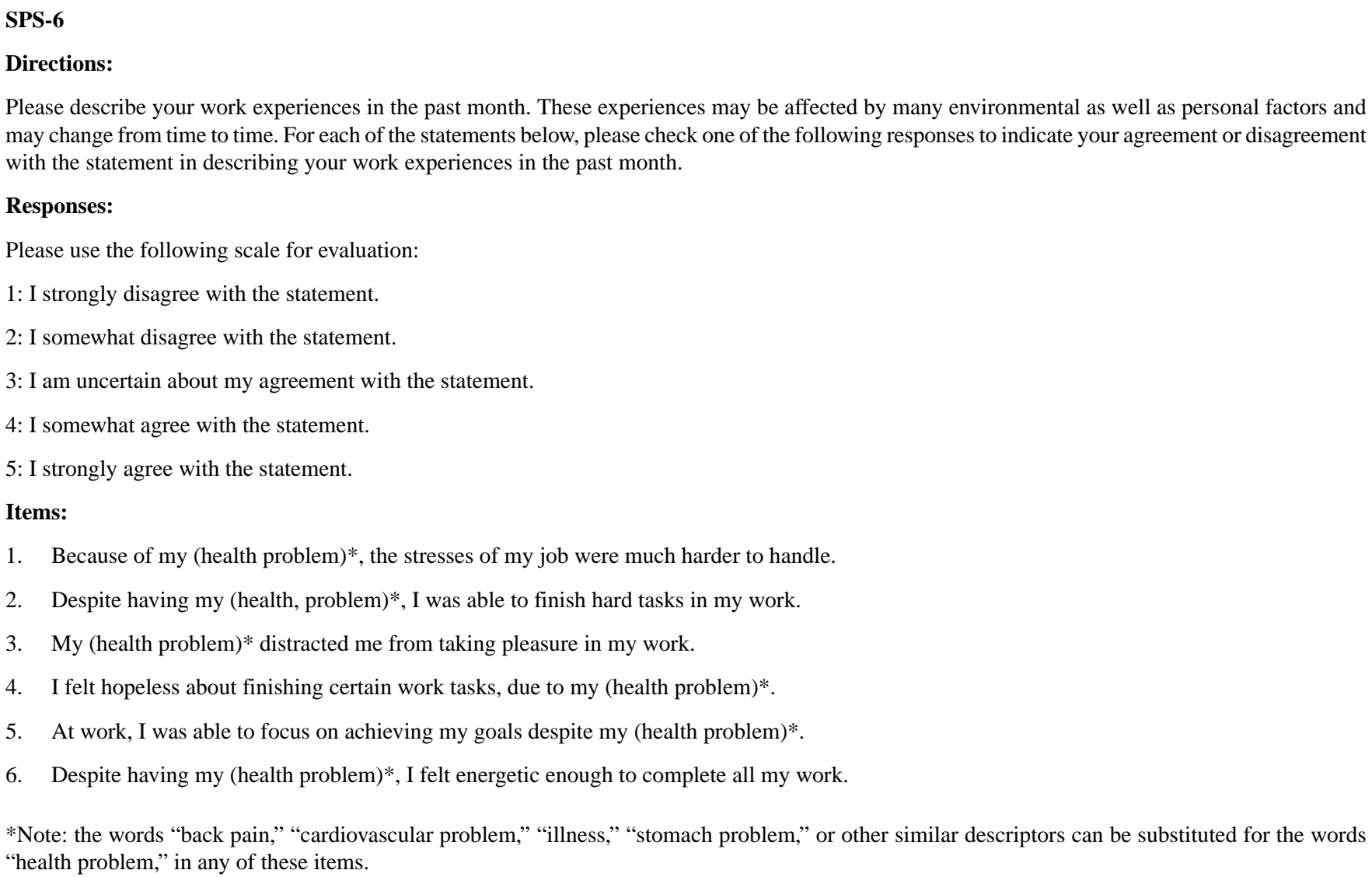

\section{Participants and Eligibility Criteria}

The eligibility criteria used for the inclusion of participants was as follows: aged 18 years or above and postgraduate student in a medical residency or multidisciplinary residency program who has been designated for activities that involve direct patient care during the COVID-19 pandemic. The exclusion criteria have been defined as the explicit or assumed refusal to participate in the study as indicated by no response to telephone or electronic form interview attempts.

\section{Study Groups}

For longitudinal tracking purposes, the exposed groups (parallel to each other) will comprise participants who are farther away from normal or reference ranges, in an unfavorable sense. This will be determined based on the following cutoff points defined for each of the instruments selected (ie, scales to assess burnout, depression, anxiety, stress, and resilience):

- DASS-21 scores

- $\quad$ Depression $>9$

- $\quad$ Anxiety $>7$

- $\quad$ Stress $>14$

- PHQ-9: scores $\geq 9$ indicate depression

- BRCS: scores $\leq 13$ indicate low resilience

In the exposed groups, we will also include participants with lower scores on the evaluation instruments for measuring autonomy at work, availability of PPE, and subjective perceptions of pedagogical adequacy of the residency program, according to the cutoff points listed below. Participants who have a work contract outside the residency program and who are directly involved in care provided to patients with COVID-19 will also be part of the exposed group. The following elements will be considered as predictors of burnout:

- Autonomy degree scale to decide conduct at work (VAS): score $\leq 4$

- Availability and adequacy of PPE for assistance activities (5-point Likert scale): score $\leq 3$

- $\quad$ Proper pedagogical organization of the medical residency program or multidisciplinary (VAS): score $\leq 5$

- External working contract: yes

- Providing care to patients with COVID-19: yes

The corresponding control groups will include participants who present burnout levels considered to be minimally satisfactory or close to the normal or reference values based on the following cutoff points defined for each of the instruments. Participants who do not have a working contract external to the residency program and who are not directly involved in the care provided to patients with COVID-19 will also be part of the control group.

- DASS-21 scores

- $\quad$ Depression $\leq 9$

- Anxiety $\leq 7$

- $\quad$ Stress $\leq 14$

- PHQ-9: score <9

- BRCS: score $>13$ 
- $\quad$ Autonomy degree scale to decide conduct at work (VAS): score $>4$

- $\quad$ Availability and adequacy of PPE for assistance activities (5-point Likert scale): score $>3$

- Proper pedagogical organization of the medical residency program or multidisciplinary (VAS): score $>5$

- External working contract: no

- Providing care to patients with COVID-19: no

\section{Sampling Size}

In estimating the required sample size, a general prevalence of about $28 \%$ for burnout syndrome among health care professionals was taken as the starting point [18]. Nevertheless, higher burnout prevalence should be expected among individuals with relevant predisposing factors. In order to identify such risk factors, we considered a difference of at least 10 percent points in the prevalence of burnout between the exposed and nonexposed groups as clinically relevant. Therefore, aiming to detect at least a 10-percent-point difference between the groups after 12 weeks of follow-up, the total sample size was initially calculated at $\mathrm{N}=686$ (ie, $\mathrm{n}=343$ for each group). However, only about $72 \%$ of the participants initially included (ie. those who did not exhibit burnout at the initial assessment) should enter the longitudinal phase and be analyzed after 12 weeks. Moreover, a dropout rate of up to $20 \%$ was expected during this longitudinal follow-up. To compensate for these expected losses, the minimum sample size was thus recalculated to be $\mathrm{N}=1144$ ( $\mathrm{n}=572$ in each group). Electronic forms were sent to all participants to collect relevant data for the research, with additional clarifications sought from the participants by telephonic contact, if necessary.

\section{Clinical Data and Outcomes}

The primary outcome will assess the differences in the incidence of burnout (determined using the OLBI instrument) between the exposure and control groups at 12 weeks of follow-up. Participants will be classified as "experiencing burnout" if their exhaustion score is $\geq 2.25$ and their disengagement score is $\geq 2.10$, considering the achieved outcome (clinically relevant difference) in case of a $\geq 10 \%$ (relative risk $\geq 1.10$ ) difference in the occurrence of burnout between groups.

Secondary outcomes will assess differences in exhaustion and disengagement scores, as determined using the OLBI instrument to assess burnout between the exposure and control groups, with 12 weeks of follow-up. The outcome will be considered if relative risk $\geq 1.15$, resulting in scores of $\geq 2.25$ and $\geq 2.10$ for exhaustion and disengagement, respectively. The prevalence of depression, anxiety, and stress symptoms at the initial visit, as measured by DASS-21 and PHQ-9 and based on previously defined cutoff scores, will also be considered as secondary outcomes. Furthermore, SPS- 6 will be administered at the baseline, with a cutoff score for clinical relevance $<18$, in case of a difference of $\geq 15 \% \quad(\mathrm{OR} \geq 1.15)$ when comparing the exposure and control groups. Absence from work in the previous 12 weeks will be evaluated descriptively through a survey (administered via Microsoft Forms) at the final evaluation stage (Figure 1). Risk factors for the occurrence of burnout will also be evaluated at the 12-week follow-up and compared between the exposure and control groups, as evaluated by relative risks and 95\% CIs. An interim analysis with data from the initial assessment (ie, cross-sectional data) will be performed to estimate the prevalence as soon as the recruitment of participants is completed.

\section{Statistical Analysis}

Outcomes based on proportions will be compared between the exposed and control groups by using the chi-square test (or Fisher exact test). Outcomes based on continuous variables will be compared by Student $t$ test (or Mann-Whitney U test). The predictive factors for burnout among the candidates will be evaluated using a generalized linear model log-binomial.

For the longitudinal follow-up, participants with scores indicative of burnout at the baseline assessment will be excluded from incidence analyses at the 12-week follow-up. Primary and secondary outcomes will be compared between participants of different professional categories (ie, medical residents and multidisciplinary residents), and potential imbalances observed between groups (ie, exposed vs control groups) will be adjusted by multiple linear regression, logistically or log-binomial, as appropriate.

\section{Ethics and Dissemination}

This study was approved by the Research Ethics Committee from the Medical School (CEP/FM) of the University of Brasília (CAAE: 33493920.0.0000.5558), through the CEP/CONEP system - Plataforma Brasil in 05/07/2020. An informed consent form will be obtained from all participants included in the study. As this is an observational study, one of the biggest risks perceived by the participants is the eventual discomfort in the face of any personal questions that may be part of the initial clinical interview conducted to determine the application of research instruments. The protocol will be registered in the Brazilian Clinical Trials Registry (Registro Brasileiro de Ensaios Clínicos) as an observational study. Undergraduate students in medicine and other undergraduate health courses will participate in the study as collaborating researchers.

\section{Results}

Data collection for this study is currently in progress. Recruitment (for the first phase) started on July 29, 2020, and ended on September 5, 2020. Analyses of data collected during this first phase is already in progress, and we estimate this to be completed by January 2021. The second phase of data collection was lauched on December 1, 2020, and we expect it to be completed by December 31, 2020; thereafter, we will begin analyses of the data collected in this phase.

\section{Discussion}

This prospective cohort study will help evaluate the prevalence of symptoms that are suggestive of mental disorders and burnout syndrome among postgraduate students of medical and multidisciplinary residencies in Brazil, as well as to determine the predictors of burnout during the COVID-19 pandemic. It is known that heath care workers, in general, have encountered worsened mental health and well-being as a result of the COVID-19 pandemic [19]. Moreover, since studies on this topic 
are quite limited especially with regard to this study population, we believe that our dataset will help to better understand and evaluate the impact of the ongoing pandemic on the mental health of these professionals; this is extremely relevant not only to scale the consequent losses but also to contribute to the planning and implementation of appropriate measures that can potentially alleviate these challenges in the near future.

\section{Acknowledgments}

We would like to thank the University Hospital of Brasília, especially the Superintendency and the Division of Teaching and Research, and EBSERH for the support provided to this study.

\section{Conflicts of Interest}

None declared.

\section{References}

1. Brasil. Recomendações de proteção aos trabalhadores dos serviços de saúde no atendimento de COVID-19 e outras síndromes gripais. Portal Brasil — Ministério da Saúde. Brasília DF: Ministério da Saúde; 2020 Apr 03. URL: https://portalarquivos. saude.gov.br/images/pdf/2020/April/16/01-recomendacoes-de-protecao.pdf [accessed 2020-07-08]

2. Fessell D, Cherniss C. Coronavirus disease 2019 (COVID-19) and beyond: micropractices for burnout prevention and emotional wellness. J Am Coll Radiol 2020 Jun;17(6):746-748 [FREE Full text] [doi: 10.1016/j.jacr.2020.03.013] [Medline: 32208139]

3. Shah K, Chaudhari G, Kamrai D, Lail A, Patel R. How essential is to focus on physician's health and burnout in coronavirus (COVID-19) pandemic? Cureus 2020 Apr 04;12(4):e7538 [FREE Full text] [doi: 10.7759/cureus.7538] [Medline: 32377486]

4. Nobre DFR, Rabiais ICM, Ribeiro PCPSV, Seabra PRC. Burnout assessment in nurses from a general emergency service. Rev Bras Enferm 2019;72(6):1457-1463 [FREE Full text] [doi: 10.1590/0034-7167-2017-0870] [Medline: $\underline{31644730]}$

5. Ishak WW, Lederer S, Mandili C, Nikravesh R, Seligman L, Vasa M, et al. Burnout during residency training: a literature review. J Grad Med Educ 2009 Dec;1(2):236-242 [FREE Full text] [doi: 10.4300/JGME-D-09-00054.1] [Medline: 21975985]

6. Bond MMK, Oliveira MSD, Bressan BJ, Bond MMK, Silva ALFAD, Merlo RC. Prevalência de Burnout entre Médicos Residentes de um Hospital Universitário. Rev Bras Educ Med 2018 Sep;42(3):97-107. [doi: 10.1590/1981-52712015v42n3rb20170034.r3]

7. Lai J, Ma S, Wang Y, Cai Z, Hu J, Wei N, et al. Factors associated with mental health outcomes among health care workers exposed to coronavirus disease 2019. JAMA Netw Open 2020 Mar 02;3(3):e203976 [FREE Full text] [doi: 10.1001/jamanetworkopen.2020.3976] [Medline: 32202646]

8. Vignola RCB, Tucci AM. Adaptation and validation of the depression, anxiety and stress scale (DASS) to Brazilian Portuguese. J Affect Disord 2014 Feb;155:104-109. [doi: 10.1016/j.jad.2013.10.031] [Medline: 24238871]

9. Szabó M, Lovibond PF. Anxiety, depression, and tension/stress in children. J Psychopathol Behav Assess 2006 Jun 13;28(3):192-202. [doi: 10.1007/s10862-005-9008-3]

10. Santos IS, Tavares BF, Munhoz TN, Almeida LSPD, Silva NTBD, Tams BD, et al. Sensibilidade e especificidade do Patient Health Questionnaire-9 (PHQ-9) entre adultos da população geral. Cad. Saúde Pública 2013 Aug;29(8):1533-1543. [doi: 10.1590/s0102-311x2013001200006]

11. Kroenke K, Spitzer RL, Williams JBW. The PHQ-9: validity of a brief depression severity measure. J Gen Intern Med 2001 Sep;16(9):606-613 [FREE Full text] [doi: 10.1046/j.1525-1497.2001.016009606.x] [Medline: 11556941]

12. Ribeiro J, Morais R, Scale C. Adaptação portuguesa da escala breve de coping resiliente. Psicol Saúde e Doenças 2010;11(1):13 [FREE Full text]

13. Sinclair VG, Wallston KA. The development and psychometric evaluation of the Brief Resilient Coping Scale. Assessment 2004 Mar;11(1):94-101. [doi: 10.1177/1073191103258144] [Medline: 14994958]

14. Jensen MP, Karoly P, Braver S. The measurement of clinical pain intensity: a comparison of six methods. Pain 1986 Oct;27(1):117-126. [doi: 10.1016/0304-3959(86)90228-9] [Medline: 3785962]

15. Sinval J, Queirós C, Pasian S, Marôco J. Transcultural adaptation of the Oldenburg Burnout Inventory (OLBI) for Brazil and Portugal. Front Psychol 2019;10:338 [FREE Full text] [doi: 10.3389/fpsyg.2019.00338] [Medline: 30914985]

16. Halbesleben JR, Buckley MR. Burnout in organizational life. J Manage 2016 Jun 23;30(6):859-879. [doi: 10.1016/j.jm.2004.06.004]

17. Paschoalin HC, Griep RH, Lisboa MTL, Bandeira de Mello DC. Transcultural adaptation and validation of the Stanford Presenteeism Scale for the evaluation of presenteeism for Brazilian Portuguese. Rev Lat Am Enfermagem 2013 Feb;21(1):388-395 [FREE Full text] [doi: 10.1590/s0104-11692013000100014] [Medline: 23546323]

18. Kumar S. Burnout and doctors: prevalence, prevention and intervention. Healthcare (Basel) 2016 Jun 30;4(3) [FREE Full text] [doi: 10.3390/healthcare4030037] [Medline: 27417625]

19. Evanoff BA, Strickland JR, Dale AM, Hayibor L, Page E, Duncan JG, et al. Work-related and personal factors associated with mental well-being during the COVID-19 response: survey of health care and other workers. J Med Internet Res 2020 Aug 25;22(8):e21366 [FREE Full text] [doi: 10.2196/21366] [Medline: 32763891] 


\section{Abbreviations}

BRCS: Brief Resilient Coping Scale

DASS-21: Depression, anxiety, and stress scale, 21 items

OLBI: Oldenburg Burnout Inventory

PHQ-9: Patient Health Questionnaire, 9 items

PPE: personal protective equipment

SPS-6: Stanford Presenteeism Scale

VAS: visual analog scale

Edited by G Eysenbach; submitted 15.09.20; peer-reviewed by W Zhang, J Hoogervorst; comments to author 06.10.20; revised version received 14.10.20; accepted 27.10.20; published 19.01.21

Please cite as:

Pinho RDNL, Costa TF, Silva NM, Barros-Areal AF, Salles ADM, Oliveira AP, Rassi C, Valero CEB, Gomes CM, Mendonça-Silva $D$, Oliveira F, Jochims I, Ranulfo I, Neves JDBS, Oliveira L, Dantas MN, Rosal M, Soares M, Kurizky P, Peterle VU, Faro YF, Gomides AP, da Mota L, Albuquerque C, Simaan CK, Amado VM

Mental Health and Burnout Syndrome Among Postgraduate Students in Medical and Multidisciplinary Residencies During the COVID-19 Pandemic in Brazil: Protocol for a Prospective Cohort Study

JMIR Res Protoc 2021;10(1):e24298

URL: https://www.researchprotocols.org/2021/1/e24298

doi: $10.2196 / 24298$

PMID: $\underline{3290246}$

CRebeca Da Nóbrega Lucena Pinho, Thais Ferreira Costa, Nayane Miranda Silva, Adriana F Barros-Areal, André De Mattos Salles, Andrea Pedrosa Oliveira, Carlos Rassi, Caroline Elizabeth Brero Valero, Ciro Martins Gomes, Dayde Mendonça-Silva, Fernando Oliveira, Isadora Jochims, Ivan Ranulfo, Juliana De Brito Seixas Neves, Lucas Oliveira, Maria Nogueira Dantas, Marta Rosal, Mayra Soares, Patrícia Kurizky, Viviane Uliana Peterle, Yasmin Furtado Faro, Ana Paula Gomides, Licia da Mota, Cleandro Albuquerque, Cezar Kozak Simaan, Veronica M Amado. Originally published in JMIR Research Protocols (http://www.researchprotocols.org), 19.01.2021. This is an open-access article distributed under the terms of the Creative Commons Attribution License (https://creativecommons.org/licenses/by/4.0/), which permits unrestricted use, distribution, and reproduction in any medium, provided the original work, first published in JMIR Research Protocols, is properly cited. The complete bibliographic information, a link to the original publication on http://www.researchprotocols.org, as well as this copyright and license information must be included. 